\title{
Computer writing integrated with conversation
}

\author{
SØREN BECK NIELSEN
}

This study contributes to current research on multiactivity and writing-in-interaction. Based on video-recordings of monitoring visits where social supervision representatives interview facility leaders, the paper examines how conversationalists administer the integration of computer writing and talk in connection with what is referred to as 'writing sequences'. The paper is organized in two overall sections. The first section examines ways in which writing sequences are initiated in relation to concurrent talk: representatives routinely commence writing while - as opposed to after - facility leaders answer questions, and facility leaders often elaborate answers whilst representatives take notes. The second section elucidates how talk and writing unfold as simultaneous activities. This analysis finds that representatives and leaders attune talk and computer typing in systematic ways. Combined, the two sections explain how writing and talk can be managed as concurrent activities.

KEYWORDS: multimodality, conversation analysis, multiactivity, writing-in-interaction 